\title{
INVESTIGATION OF CRITICAL MATERIAL ATTRIBUTES OF NANOCELLULOSE IN TABLETS
}

\author{
ROSHNI VORA ${ }^{1,2 *}$, YAMINI SHAH ${ }^{2}$ \\ ${ }^{1}$ Gujarat Technological University, Chandkheda, Ahmedabad, Gujarat, India. ${ }^{2}$ Department of Pharmaceutics and Pharmaceutical \\ Technology, L.M.College of Pharmacy, Ahmedabad, Gujarat, India. Email: mehtaroshni1989@gmail.com
}

Received: 24 April 2019, Revised and Accepted: 29 May 2019

ABSTRACT

Objective: The present work aims to compare powder flow properties and post-compression characteristics of acid hydrolysed nanocellulose (AHNC) a novel excipient with microcrystalline cellulose (MCC PH200) to demonstrate the application and performance of AH-NC.

Methods: I-optimal design was applied separately for both the excipient, i.e., MCC PH200 and AH-NC. Independent variables were MCC PH200 as diluent (X1), AH-NC as diluent (X1), starch as disintegrant (X2), and PVP K30 as dry binder (X3). The dependent variables in design were Carr's index (CI) (R1), angle of repose (AR) (R2), hardness (R3), friability (R4), disintegration time (DT) (R5), and T90 (R6).

Results: Fourier-transform infrared spectroscopy (FTIR) and Differential scanning calorimetry (DSC) studies showed the compatibility of the drug with an excipient. CI was found in the range of $8 \%-17.84 \%$ for MCC PH200 and 5.25\%-11.94\% for AH-NC. AR was found in the range of 31.48-37.66 for MCC PH200 and 29.62-35.30 for AH-NC. The values of friability, DT, and T90 were almost identical in both the cases.

Conclusion: Not only does AH-NC demonstrates better flow properties but also problems of weight variation and content uniformity are not observed when compared to MCC PH200. Hence, AH-NC is more suitable as an excipient for modern high-speed rotary tablet press.

Keywords: Microcrystalline cellulose PH200, Acid hydrolysed nanocellulose, Novel excipient, I-optimal design, Powder flow properties.

(C) 2019 The Authors. Published by Innovare Academic Sciences Pvt Ltd. This is an open access article under the CC BY license (http://creativecommons. org/licenses/by/4. 0/) DOI: http://dx.doi.org/10.22159/ajpcr.2019.v12i7.33725

\section{INTRODUCTION}

The production of nanocellulose (NC) and their application in different areas has gained increasing attention recently due to their low density, high surface area to volume ratio, higher Young's modulus, higher tensile strength, thermal stability, and biodegradable nature [1]. Extraction of NC has been carried out by acid hydrolysed (AH), enzymatic hydrolysed, homogenization, microfluidization, grinding, cryocrushing, and ultrasonication [2,3] from algae, tunicates, bacteria, and natural plant [4]. Application of $\mathrm{NC}$ as a nanocomposite has been studied [5-8]. However, application of NC in the pharmaceutical field has not been reported so far which basically is the objective of this study - to evaluate the usability of $\mathrm{NC}$ as novel tableting excipient produced by processing corn husk an agricultural waste, through AH. For that purpose, AH-NC was compared to commercially available grades of microcrystalline cellulose (MCC): Avicel PH 200. MCC was chosen for comparison due to its similarity to AH-NC in chemical structure. Besides, Avicel PH 200 is the most common grade of MCC used in tableting. Glibenclamide (GLB), an oral hypoglycemic agent for the treatment in non-insulin-dependent diabetes mellitus, was selected as a model drug in the present study [9-11]. Design Expert ${ }^{\circledR}$ Version 12 was used for the data treatment of I-optimal design to ensure optimum use of time and cost to obtain a high quality of powder flow property using direct compression $[12,13]$.

\section{MATERIALS AND METHODS}

\section{Materials}

GLB from Cadila Pharmaceuticals Ltd. (India), MCC PH 200 (Avicel $^{\circledR}$ PH200) from Signet Pharma (India), PVP K30 from J H Nanhang Life Sciences Co. Ltd. (China), starch, magnesium stearate, and talc from ACME Chemicals, Mumbai (India), were obtained as a gift sample. Indigenously produced $\mathrm{AH}-\mathrm{NC}$ from corn husk.

\section{Methods}

Fourier-transform infrared spectroscopy (FTIR)

FTIR spectra of a drug, a physical mixture of drug and excipients, were recorded using KBr discs on a Perkin-Elmer FTIR spectrometer. Spectrum range was 4,000-400/cm [14-17].

\section{Differential scanning calorimeter (DSC)}

Thermal properties of a drug, a physical mixture of drug and excipients, were investigated by DSC on a thermal analyzer (DSC-Thermal Analysis: Shimadzu Corporation). About $20 \mathrm{mg}$ of each sample was heated from room temperature to $300^{\circ} \mathrm{C}$ at a rate of $10^{\circ} \mathrm{C} / \mathrm{min}$ under nitrogen [14-17].

\section{Preparation of GLB tablet}

All the ingredients weighed accurately and passed through sieve number 60. Tablets were prepared by direct compression using a rotary press (Rimek, Karnavati Engineering Ltd., Gujarat). The total tablet weight (GLB, starch, PVP K30, MCC PH200/AH-NC, magnesium stearate, and talc) was $160 \mathrm{mg}$ each with $\approx 3.2 \mathrm{~mm}$ thickness and $8 \mathrm{~mm}$ in diameter. Experimental runs, their factor combinations, and the translation of the coded levels to the experimental units used in the study are summarized in Table 1. Composition of all prepared batches is mentioned in Table 2 .

\section{Evaluation of GLB tablets}

Pre-compression parameters

Carr's index $(\mathrm{CI})$

Bulk density ( $\rho b)$ and the tapped density ( $\rho t)$ of the sample were determined with a bulk/tap density test apparatus (Elecrolab, EDT1020). CI was calculated as 100 times; the ratio of the difference between the tapped density and bulk density to the tapped density was calculated by utilizing the following equation [18-20].

$C I=([\rho t-\rho b] / \rho t) \times 100$ 
Table 1: Experimental runs for the glibenclamide tablet with coded values

\begin{tabular}{|c|c|c|c|c|}
\hline Independent variables & Name & Unit & 0 (low) & 1 (high) \\
\hline \multicolumn{5}{|c|}{ Tablet formulation using MCC PH 200} \\
\hline $\mathrm{X} 1$ & Starch & $\%$ & 4 & 8 \\
\hline $\mathrm{X} 2$ & PVP K30 & $\%$ & 2 & 10 \\
\hline X3 & MCC PH 200 & $\%$ & 79.87 & 87.87 \\
\hline \multicolumn{5}{|c|}{ Tablet formulation using AH-NC } \\
\hline $\mathrm{X} 1$ & Starch & $\%$ & 4 & 8 \\
\hline X2 & PVP K30 & $\%$ & 2 & 10 \\
\hline $\mathrm{X} 3$ & $\mathrm{AH}-\mathrm{NC}$ & $\%$ & 79.87 & 87.87 \\
\hline \multicolumn{5}{|c|}{ Dependent variables and their desired ranges } \\
\hline Dependent variables & Name & Unit & MCC PH 200 & AH-NC \\
\hline R1 & $\mathrm{CI}$ & $\%$ & $<10-15$ & $<10-15$ \\
\hline R2 & $\mathrm{AR}$ & $\theta$ & $25-35$ & $25-35$ \\
\hline R3 & Hardness & $\mathrm{kg} / \mathrm{cm}^{2}$ & $3-5$ & $3-5$ \\
\hline R4 & Friability & $\%$ & $0.2-0.9$ & $0.2-0.9$ \\
\hline R5 & Disintegration time & $\mathrm{Sec}$ & $40-270$ & $40-270$ \\
\hline R6 & T90 & Min & $90-110$ & $90-110$ \\
\hline
\end{tabular}

MCC: Microcrystalline cellulose, AH-NC: Acid hydrolysed-nanocellulose, AR: Angle of repose, CI: Carr's index

Table 2: Composition of all formulations of glibenclamide tablet

\begin{tabular}{|c|c|c|c|c|c|c|c|c|c|c|c|c|c|c|c|c|}
\hline & \multicolumn{16}{|c|}{ Batches } \\
\hline & 1 & 2 & 3 & 4 & 5 & 6 & 7 & 8 & 9 & 10 & 11 & 12 & 13 & 14 & 15 & 16 \\
\hline \multicolumn{17}{|c|}{ Tablet formulation using MCC PH 200} \\
\hline \multicolumn{17}{|l|}{ Ingredients (\%) } \\
\hline Glibenclamide & 3.1 & 3.1 & 3.1 & 3.1 & 3.1 & 3.1 & 3.1 & 3.1 & 3.1 & 3.1 & 3.1 & 3.1 & 3.1 & 3.1 & 3.1 & 3.1 \\
\hline Starch & 6.4 & 8.0 & 4.6 & 4.0 & 6.2 & 6.4 & 6.2 & 8.0 & 4.0 & 4.6 & 4.6 & 4.0 & 4.0 & 6.4 & 8.0 & 6.4 \\
\hline PVP K30 & 2.0 & 5.8 & 5.6 & 2.0 & 6.0 & 7.7 & 6.0 & 2.3 & 3.9 & 5.6 & 5.6 & 10.0 & 7.9 & 2 & 4.0 & 7.6 \\
\hline Talc & 1 & 1 & 1 & 1 & 1 & 1 & 1 & 1 & 1 & 1 & 1 & 1 & 1 & 1 & 1 & 1 \\
\hline $\begin{array}{l}\text { Magnesium } \\
\text { stearate }\end{array}$ & 2 & 2 & 2 & 2 & 2 & 2 & 2 & 2 & 2 & 2 & 2 & 2 & 2 & 2 & 2 & 2 \\
\hline \multicolumn{17}{|c|}{ Tablet formulation using AH-NC } \\
\hline \multicolumn{17}{|c|}{ Ingredients (\%) } \\
\hline Glibenclamide & 3.1 & 3.1 & 3.1 & 3.1 & 3.1 & 3.1 & 3.1 & 3.1 & 3.1 & 3.1 & 3.1 & 3.1 & 3.1 & 3.1 & 3.1 & 3.1 \\
\hline Starch & 6.4 & 8.0 & 4.6 & 4.0 & 6.2 & 6.4 & 6.2 & 8.0 & 4.0 & 4.6 & 4.6 & 4.0 & 4.0 & 6.4 & 8.0 & 6.4 \\
\hline $\mathrm{AH}-\mathrm{NC}$ & 85.52 & 80.08 & 83.63 & 87.87 & 81.68 & 79.87 & 81.68 & 83.58 & 85.89 & 83.63 & 83.63 & 79.87 & 81.92 & 85.52 & 81.81 & 79.87 \\
\hline Talc & 1 & 1 & 1 & 1 & 1 & 1 & 1 & 1 & 1 & 1 & 1 & 1 & 1 & 1 & 1 & 1 \\
\hline $\begin{array}{l}\text { Magnesium } \\
\text { stearate }\end{array}$ & 2 & 2 & 2 & 2 & 2 & 2 & 2 & 2 & 2 & 2 & 2 & 2 & 2 & 2 & 2 & 2 \\
\hline
\end{tabular}

MCC: Microcrystalline cellulose, AH-NC: Acid hydrolysed-nanocellulose

Hausner's ratio (HR)

HR is the ratio of bulked density to the tapped density. HR was calculated according to the following equation [18-20].

$H R=\rho b / \rho t$

\section{Angle of repose (AR)}

It is defined as the angle between the free surfaces of a pile of powder to a horizontal plane. In the present study, the AR was determined using a fixed cone method [18-20]. The sample was carefully poured through the funnel until the apex of the cone, thus formed just touched the tip of the funnel. The mean radius (r) and height $(\mathrm{h})$ of the heap were measured and the AR was calculated from the following equation:

$\tan \theta=h / r$

\section{Post-compression parameters}

Hardness

Hardness is termed as the tablet crushing strength or defined as the force required breaking a tablet in a diametric compression test. It was recorded using Monsanto hardness tester. Hardness of three tablets was measured and mean and the standard deviation was calculated and reported and expressed in terms of $\mathrm{kg} / \mathrm{cm}^{2}$ [21-23].

Friability

Friability of the tablets was tested using Roche friability tester. Ten tablets (Fs) were placed in friabilator and operated at $25 \mathrm{rpm}$ for $4 \mathrm{~min}$ [21-23]. Afterward, the fines were removed by sieving through a $250-\mu \mathrm{m}$ mesh and the fraction above $250 \mu \mathrm{m}$ mesh (Fa) was used to calculate the friability of tablets according to the following equation:

Friability $=(\mathrm{Fs}-\mathrm{Fa}) / \mathrm{Fa} \times 100$

Weight variation

Twenty tablets were weighed individually and then the average weight was calculated. The weight of an individual tablet is then compared to the average. The tablet passes the test if no more than two tablets are outside the percentage limit [21].

Disintegration time (DT)

In vitro DT was performed by USP disintegration apparatus at $50 \mathrm{rpm}$. Phosphate buffer (pH 6.8), $600 \mathrm{ml}$ was used as disintegration medium, the temperature was maintained at $37^{\circ} \mathrm{C} \pm 2^{\circ} \mathrm{C}$ and one tablet was 
placed in each of the six basket tubes of the apparatus and one disc was added to each tube. Time taken for the complete disintegration of the tablet was noted [21].

\section{In vitro dissolution}

GLB release was determined using a dissolution apparatus USP type II (Paddle type). Tablet was added with sinkers in a dissolution medium consisting of $900 \mathrm{ml} 0.05 \mathrm{M}$, pH 7.5 phosphate buffer and was stirred at $50 \mathrm{rpm}$ at $37^{\circ} \mathrm{C} \pm 0.5^{\circ} \mathrm{C}$. Five $\mathrm{ml}$ of sample was withdrawn at defined time intervals and was replaced with the same volume of fresh dissolution media. The samples were analyzed spectrophotometrically (UV-1700, Shimadzu Corp., Kyoto, Japan) at $231.5 \mathrm{~nm}$ (Cruz-Antonio $83)$. Dissolution tests $(n=3)$ were carried out for all the batches and the percentage drug released was calculated using a standard calibration curve [24].

\section{RESULTS AND DISCUSSION}

\section{FTIR}

Spectrum of GLB and physical mixture of GLB with excipients is shown in Fig. 1. GLB showed carbonyl stretching at $1712.67 / \mathrm{cm}$, symmetrical and asymmetrical sulfonyl stretching at 1161.07 and 1344.29/ $\mathrm{cm}$, respectively, and amide stretching at 3315.41 and $3365.55 / \mathrm{cm}$. Comparison of functional group peaks of GLB and physical mixture revealed that there were no major changes observed for characteristic peaks which confirm the absence of interaction between drug and the excipients [10].
DSC

DSC thermograms of GLB and physical mixture of GLB with other excipients are compared as shown in Fig. 2. A sharp endothermic peak at $175.58^{\circ} \mathrm{C}$ in the thermogram of GLB was observed. Characteristic peak of GLB was observed at $175.22^{\circ} \mathrm{C}$ in a physical mixture containing MCC PH200, whereas peak of a mixture containing AH-NC was observed at $175.23^{\circ} \mathrm{C}$. This confirmed that no major changes were observed in characteristic peaks showing compatibility between drug and excipients used in the formulation [11].

\section{Responses for GLB tablet}

Experimental trials (16 batches) and their observed responses are shown in Tables 3 and 4. From the results, it is suggested that the quadratic model is the best fit model for all responses.

\section{CI (R1)}

Model F-value for MCC PH200 is 479.04 and for AH-NC is 6.01 implies that the model is significant. The results of multiple regression analysis indicate a fairly high value of correlation coefficient, i.e., 0.9979 for MCC PH200 and for AH-NC is 0.8662. It is concluded that the value of $\mathrm{CI}$ can be predicted within the design space, with fair accuracy. The interaction terms are statistically significant in nature as shown in Table 5.

The highest value of the coefficient was seen with starch in the mathematical model. The reason for poor fluidity is starch, due to the

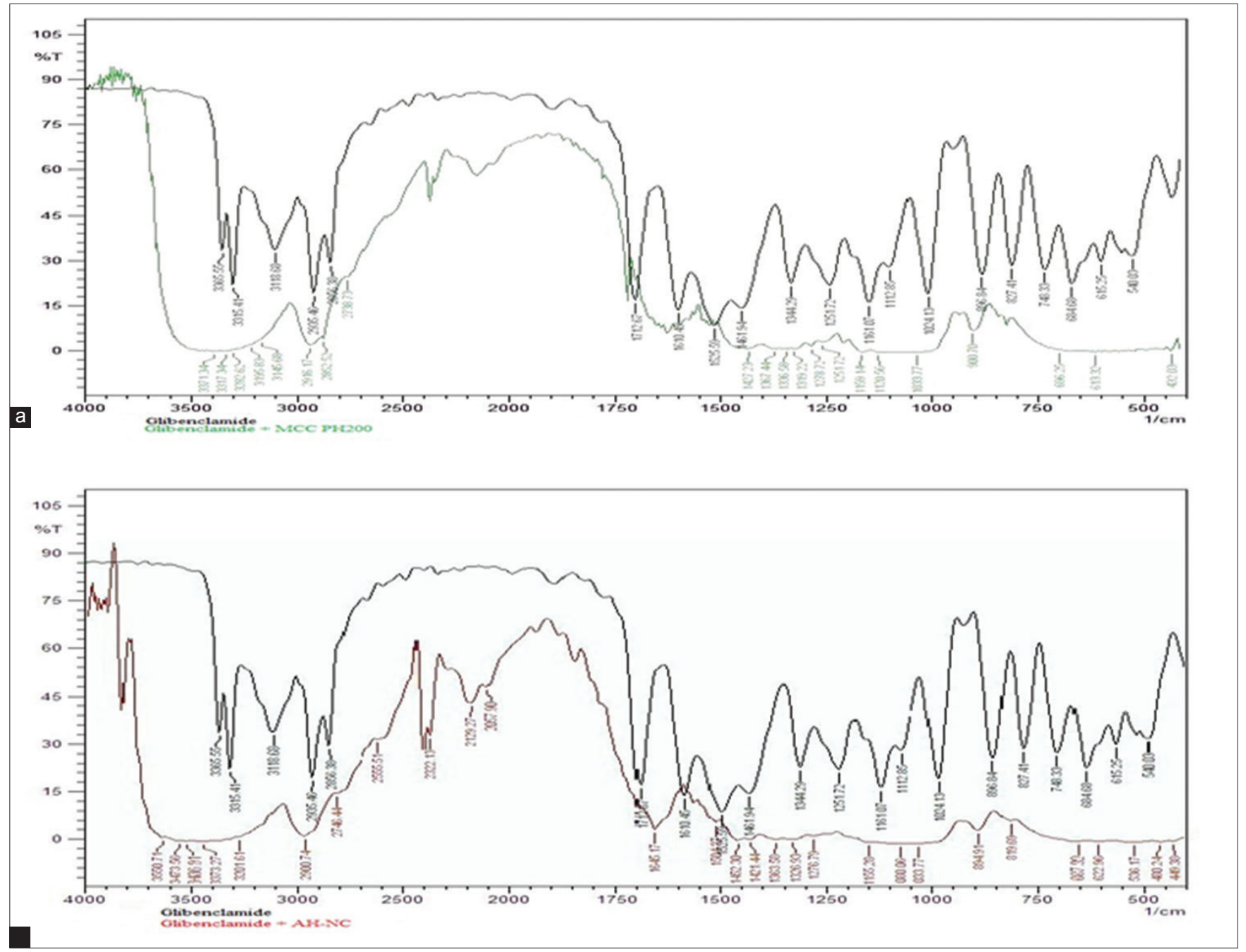

Fig. 1: Fourier-transform infrared spectroscopy spectra of a) GLB and GLB + MCC PH200 and b) GLB and GLB + AH-NC 


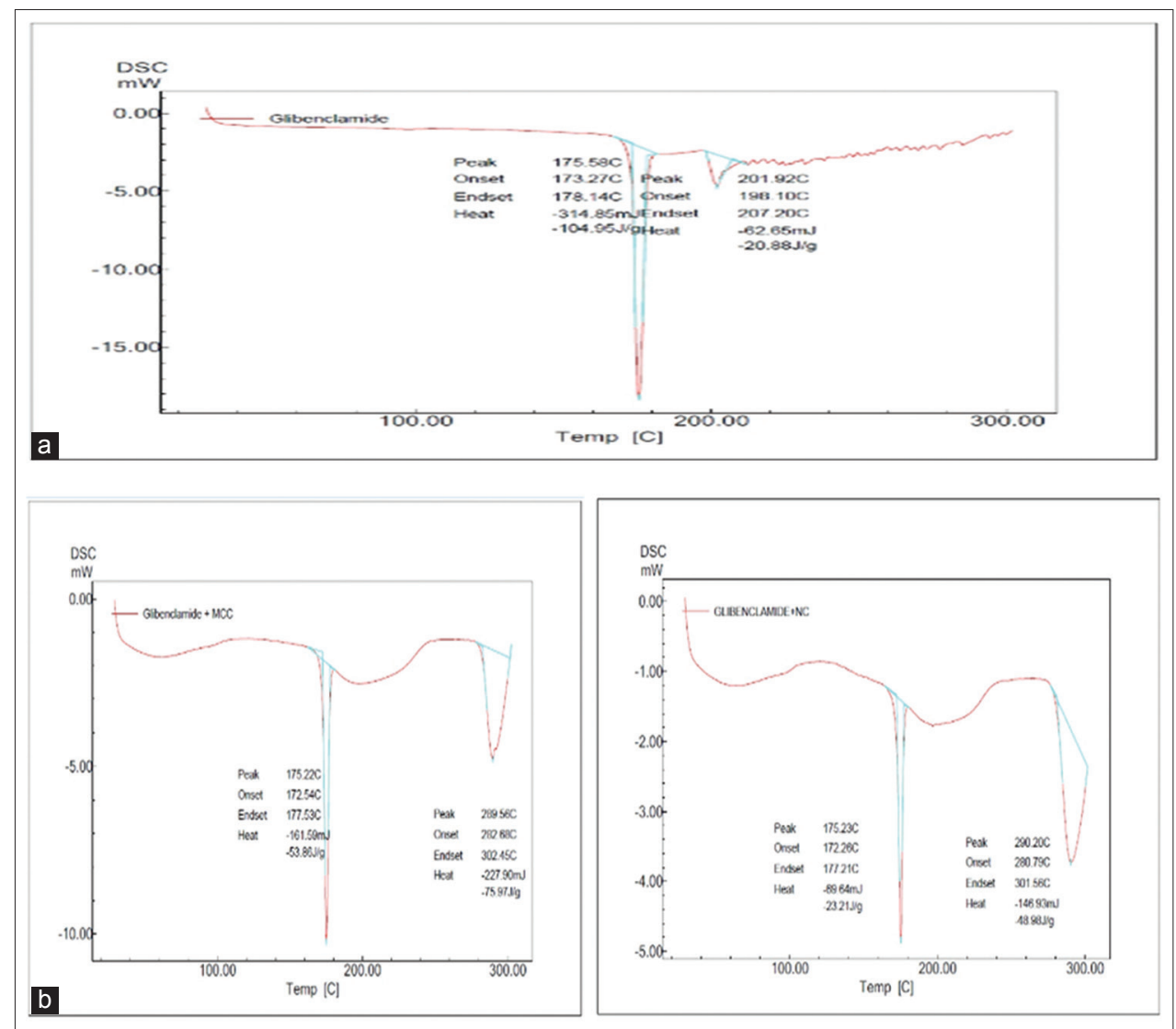

Fig. 2: Differential scanning calorimeter thermogram of a) GLB b) GLB + MCC PH200 and c) GLB + AH-NC

Table 3: Observed responses of glibenclamide tablets using microcrystalline cellulose PH200

\begin{tabular}{|c|c|c|c|c|c|c|c|c|}
\hline \multirow[t]{2}{*}{ Response } & \multicolumn{8}{|c|}{ Batches } \\
\hline & 1 & 2 & 3 & 4 & 5 & 6 & 7 & 8 \\
\hline $\mathrm{CI}^{*}$ & $13.31 \pm 3.62$ & $12.29 \pm 7.03$ & $9.06 \pm 3.81$ & $13.42 \pm 6.05$ & $8.52 \pm 1.62$ & $9.48 \pm 1.48$ & $8.00 \pm 3.17$ & $17.84 \pm 6.67$ \\
\hline $\mathrm{AR}^{*}$ & $35.27 \pm 1.44$ & $31.48 \pm 5.33$ & $34.67 \pm 4.53$ & $33.72 \pm 0.88$ & $34.34 \pm 1.38$ & $34.54 \pm 3.66$ & $34.07 \pm 4.45$ & $32.03 \pm 0.81$ \\
\hline Hardness* & $4.90 \pm 0.36$ & $3.53 \pm 0.42$ & $4.77 \pm 0.38$ & $4.83 \pm 0.21$ & $4.73 \pm 0.31$ & $4.40 \pm 1.06$ & $4.87 \pm 0.23$ & $3.30 \pm 0.70$ \\
\hline Friability & 0.47 & 0.92 & 0.89 & 0.56 & 0.77 & 0.56 & 0.76 & 0.75 \\
\hline $\mathrm{DT}^{* *}$ & $295.17 \pm 1.94$ & $57.33 \pm 4.63$ & $168.00 \pm 1.26$ & $172.67 \pm 1.75$ & $185.17 \pm 1.47$ & $140.83 \pm 1.47$ & $185.17 \pm 1.41$ & $150.83 \pm 2.07$ \\
\hline T90* & $26.72 \pm 0.13$ & $22.72 \pm 0.32$ & $26.68 \pm 0.33$ & $41.44 \pm 0.13$ & $17.16 \pm 0.10$ & $20.22 \pm 0.32$ & $15.43 \pm 0.33$ & $21.33 \pm 0.11$ \\
\hline Weight variation & 160.49 & 160.06 & 159.99 & 160.3 & 160.05 & 160.23 & 161.17 & 161.2 \\
\hline \multirow[t]{2}{*}{ Response } & \multicolumn{8}{|c|}{ Batches } \\
\hline & 9 & 10 & 11 & 12 & 13 & 14 & 15 & 16 \\
\hline $\mathrm{CI}^{*}$ & $10.84 \pm 8.15$ & $9.06 \pm 3.81$ & $9.06 \pm 3.81$ & $16.50 \pm 4.42$ & $11.83 \pm 1.82$ & $13.83 \pm 1.87$ & $14.33 \pm 1.70$ & $9.42 \pm 1.05$ \\
\hline $\mathrm{AR}^{*}$ & $34.21 \pm 5.27$ & $35.92 \pm 1.52$ & $35.92 \pm 1.52$ & $37.66 \pm 2.14$ & $36.56 \pm 1.02$ & $35.27 \pm 1.44$ & $31.48 \pm 5.33$ & $34.62 \pm 0.92$ \\
\hline Hardness* & $4.27 \pm 0.31$ & $4.80 \pm 0.20$ & $4.67 \pm 0.15$ & $4.53 \pm 0.06$ & $4.33 \pm 0.42$ & $4.47 \pm 0.23$ & $3.63 \pm 0.15$ & $4.60 \pm 0.20$ \\
\hline Friability & 0.88 & 0.8 & 0.89 & 0.7 & 0.93 & 0.47 & 0.92 & 0.66 \\
\hline T90* & $40.78 \pm 0.32$ & $21.47 \pm 0.33$ & $20.33 \pm 0.24$ & $32.33 \pm 0.28$ & $36.8 \pm 0.31$ & $23.23 \pm 0.35$ & $36.25 \pm 0.39$ & $39.06 \pm 0.43$ \\
\hline Weight variation & 161.03 & 161.16 & 161.29 & 161.42 & 161.55 & 161.69 & 161.82 & 161.95 \\
\hline
\end{tabular}

*Average of three determinations, ${ }^{* *}$ An average of six determinations. AR: Angle of repose, CI: Carr's index, DT: Disintegration time

presence of moisture in it and fine particles. Curved lines in response surface plot indicate non-linear relation between independent and dependent variables as shown in Fig. 3.

\section{AR (R2)}

Model $F$-value for MCC PH200 is 34.99 and for AH-NC is 5.18 implies that the model is significant. The results of multiple regression analysis indicate a fairly high value of correlation coefficient, i.e., 0.972 for MCC PH200 and for AH NC is 0.8493. It is concluded that the value of the
AR can be predicted within the design space, with fair accuracy. The interaction terms are statistically significant in nature as shown in Table 6.

Starch showed an insignificant effect on the AR due to lowest coefficient value, i.e., 16.81 for MCC PH200 and 10.95 for AH-NC. As shown in Fig. 4, left corner red in color shows that AR is on the higher side. The high amount of PVP K30, MCC PH200, and AH-NC showed decline in AR. 
Table 4: Observed responses of glibenclamide tablets using AH-NC

\begin{tabular}{|c|c|c|c|c|c|c|c|c|}
\hline \multirow[t]{2}{*}{ Response } & \multicolumn{8}{|c|}{ Batches } \\
\hline & 1 & 2 & 3 & 4 & 5 & 6 & 7 & 8 \\
\hline $\mathrm{CI}^{*}$ & $5.25 \pm 2.06$ & $11.94 \pm 0.93$ & $6.41 \pm 1.39$ & $9.26 \pm 2.86$ & $5.81 \pm 2.17$ & $7.03 \pm 0.34$ & $10.11 \pm 4.06$ & $7.89 \pm 8.66$ \\
\hline Hardness* & $5.23 \pm 0.21$ & $3.20 \pm 0.20$ & $5.00 \pm 0.10$ & $5.73 \pm 0.31$ & $4.20 \pm 0.20$ & $5.27 \pm 0.31$ & $6.40 \pm 0.87$ & $3.13 \pm 0.99$ \\
\hline Friability & 0.81 & 0.46 & 0.86 & 1.09 & 0.65 & 0.61 & 0.65 & 0.64 \\
\hline $\mathrm{DT}^{* *}$ & $254.00 \pm 3.03$ & $47.62 \pm 1.68$ & $163.44 \pm 3.22$ & $169.17 \pm 1.47$ & $279.17 \pm 1.72$ & $131.75 \pm 1.08$ & $175.00 \pm 0.63$ & $140.82 \pm 0.92$ \\
\hline Т90* & $26.60 \pm 0.33$ & $43.84 \pm 0.48$ & $35.56 \pm 0.33$ & $27.77 \pm 0.13$ & $35.00 \pm 0.10$ & $43.53 \pm 0.32$ & $35.00 \pm 0.42$ & $34.77 \pm 0.11$ \\
\hline Weight variation & 161.45 & 160.91 & 163.17 & 162.87 & 161.11 & 163.05 & 164.22 & 160.65 \\
\hline \multirow[t]{2}{*}{ Response } & \multicolumn{8}{|c|}{ Batches } \\
\hline & 9 & 10 & 11 & 12 & 13 & 14 & 15 & 16 \\
\hline $\mathrm{CI}^{*}$ & $8.38 \pm 3.96$ & $7.46 \pm 2.87$ & $7.46 \pm 2.87$ & $6.39 \pm 1.15$ & $7.32 \pm 3.88$ & $5.25 \pm 2.06$ & $9.64 \pm 13.59$ & $7.74 \pm 4.76$ \\
\hline $\mathrm{AR}^{*}$ & $30.52 \pm 1.48$ & $35.27 \pm 1.44$ & $35.30 \pm 2.03$ & $29.62 \pm 2.18$ & $31.95 \pm 3.30$ & $34.21 \pm 5.27$ & $31.48 \pm 5.33$ & $32.32 \pm 1.26$ \\
\hline Hardness* & $4.20 \pm 0.20$ & $5.00 \pm 0.10$ & $4.69 \pm 0.20$ & $4.68 \pm 0.22$ & $4.67 \pm 0.23$ & $4.67 \pm 0.25$ & $4.66 \pm 0.26$ & $4.65 \pm 0.28$ \\
\hline Friability & 0.99 & 0.86 & 0.86 & 0.92 & 0.91 & 0.81 & 0.53 & 0.51 \\
\hline Т90* & $28.00 \pm 0.42$ & $35.56 \pm 0.33$ & $35.56 \pm 0.24$ & $30.96 \pm 0.28$ & $24.24 \pm 0.31$ & $35.00 \pm 0.35$ & $34.21 \pm 0.39$ & $43.53 \pm 0.43$ \\
\hline Weight variation & 161.45 & 161.43 & 161.93 & 161.91 & 160.79 & 161.88 & 160.91 & 163.39 \\
\hline
\end{tabular}

*Average of three determinations, ${ }^{* *}$ An average of six determinations. AR: Angle of repose, CI: Carr's index, DT: Disintegration time

Table 5: Full model in coded form for Carr's index

\begin{tabular}{lllllll}
\hline & A & B & C & AB & AC & BC \\
\hline MCC PH 200 & & & & & & \\
CI & 47.4699 & 16.4503 & 13.5083 & -3.50830 & -3.50830 & -3.5083 \\
p & $<0.0001$ & $<0.0001$ & $<0.0001$ & $<0.0001$ & $<0.0001$ & $<0.0001$ \\
AH-NC & & & & & -46.9373 & 2.44815 \\
CI & 29.7483 & 6.14168 & 8.95201 & -24.7036 & 0.0015 & 0.5209 \\
p & 0.1875 & 0.1875 & 0.1875 & 0.0429 & \\
\hline
\end{tabular}

MCC: Microcrystalline cellulose, AH-NC: Acid hydrolysed-nanocellulose, CI: Carr's index

Table 6: Full model in coded form for an angle of repose

\begin{tabular}{|c|c|c|c|c|c|c|}
\hline & A & B & C & $\mathbf{A B}$ & AC & BC \\
\hline \multicolumn{7}{|c|}{ МCC РН 200} \\
\hline $\mathrm{AR}$ & 16.8085 & 37.7675 & 33.9237 & 14.3515 & 29.0784 & -2.54291 \\
\hline $\mathrm{p}$ & $<0.0001$ & $<0.0001$ & $<0.0001$ & 0.0119 & 0.0001 & 0.1468 \\
\hline \multicolumn{7}{|c|}{$\mathrm{AH}-\mathrm{NC}$} \\
\hline $\mathrm{AR}$ & 10.9593 & 29.6747 & 30.4561 & 40.5637 & 44.3385 & 9.95272 \\
\hline $\mathrm{p}$ & 0.5574 & 0.5574 & 0.5574 & 0.0031 & 0.0020 & 0.0204 \\
\hline
\end{tabular}

MCC: Microcrystalline cellulose, AH-NC: Acid hydrolysed-nanocellulose, AR: Angle of repose

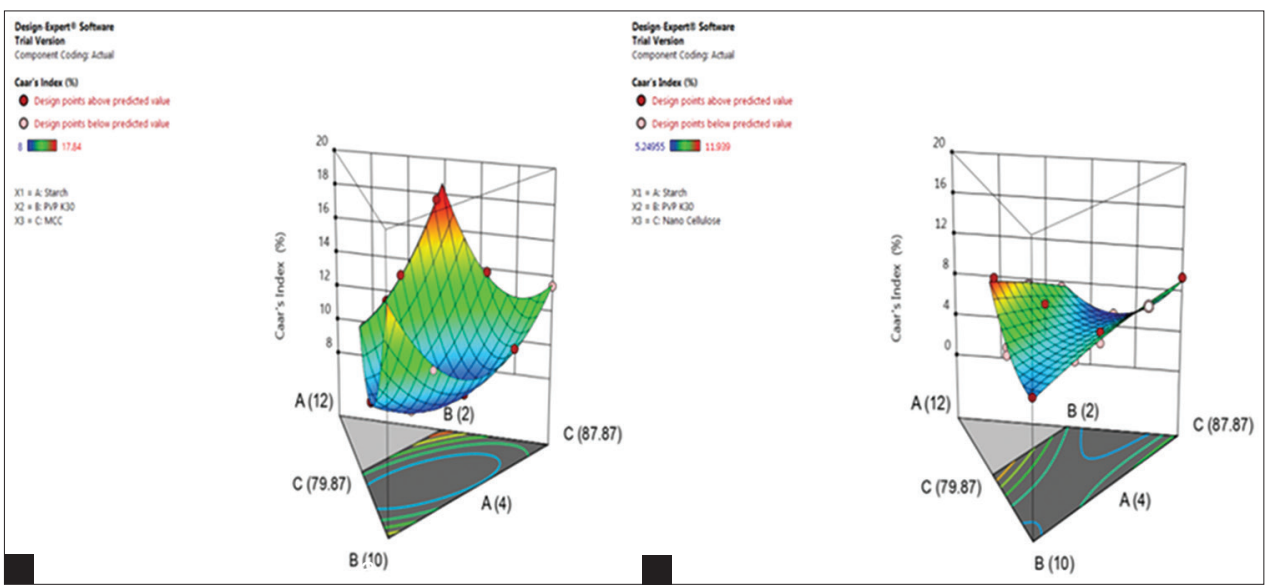

Fig. 3: Response surface plot for Carr's index a) MCC PH200 b) AH-NC 


\section{Hardness of tablets (R3)}

Model $F$-value for MCC PH200 is 17.72 and for AH-NC is 7.72 implies that the model is significant. The results of multiple regression analysis indicate a fairly high value of correlation coefficient, i.e., 0.947 for MCC $\mathrm{PH} 200$ and for AH-NC is 0.8911. It is concluded that the value of the hardness can be predicted within the design space, with fair accuracy. The interaction terms are statistically significant in nature as shown in Table 7.

The coefficient associated with starch is negative, i.e., -3.75 for MCC PH200 and -8.25 for AH-NC. As shown in Fig. 5, if the amount of starch is increased in the powder blend, the hardness of the tablets will reduce. PVP K30, MCC PH200, and AH-NC showed positive coefficients. The hardness of the tablets should increase if PVP K30 and/or MCC PH200/ $\mathrm{AH}-\mathrm{NC}$ are increased in the powder blend.

\section{Friability of tablets (R4)}

Model $F$-value for MCC PH200 is 53.88 and for AH-NC is 160.83 implies that the model is significant. The results of multiple regression analysis indicate a fairly high value of correlation coefficient, i.e., 0.981 for MCC PH200 and for AH NC is 0.9938. It is concluded that the value of the friability can be predicted within the design space, with fair accuracy. The interaction terms are statistically significant in nature as shown in Table 8.

As shown in Fig. 6, plots show a steep change in the values of friability of the GLB tablets. It may be concluded from the contour plot of friability of GLB tablets that low concentration of PVP K30 is not favorable to keep the friability below $1 \%$. PVP K30 played a key role in managing the mechanical strength of the tablets.

Table 7: Full model in coded form for hardness

\begin{tabular}{lllllll}
\hline & A & B & C & AB & AC & BC \\
\hline MCC PH 200 & & & & & & \\
$\quad$ Hardness & -3.74738 & 4.42348 & 4.68266 & 12.6804 & 11.9954 & -0.425618 \\
p & 0.0003 & 0.0003 & 0.0003 & $<0.0001$ & $<0.0001$ & 0.5231 \\
AH-NC & & 4.63199 & 4.93067 & 22.332 & 19.8701 & -1.1776 \\
$\quad$ Hardness & -8.25355 & 0.0527 & 0.0527 & 0.0003 & 0.0008 & 0.4251 \\
$\quad$ p & 0.0527 & &
\end{tabular}

MCC: Microcrystalline cellulose, AH-NC: Acid hydrolysed-nanocellulose

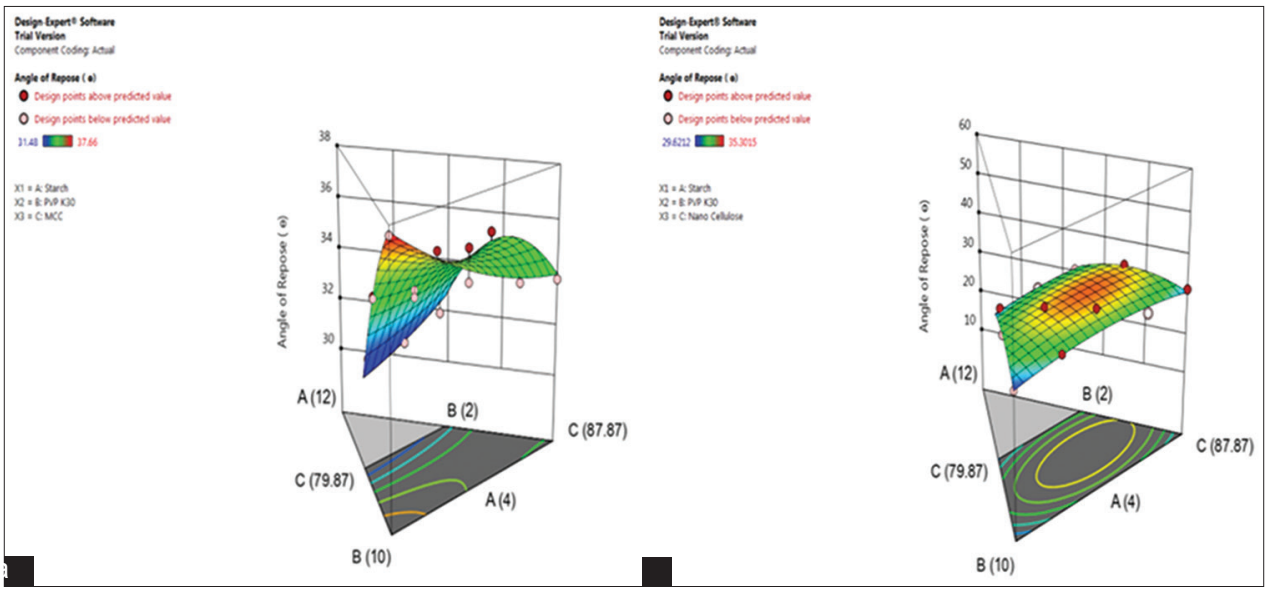

Fig. 4: Response surface plot for an angle of repose a) MCC PH200 b) AH-NC

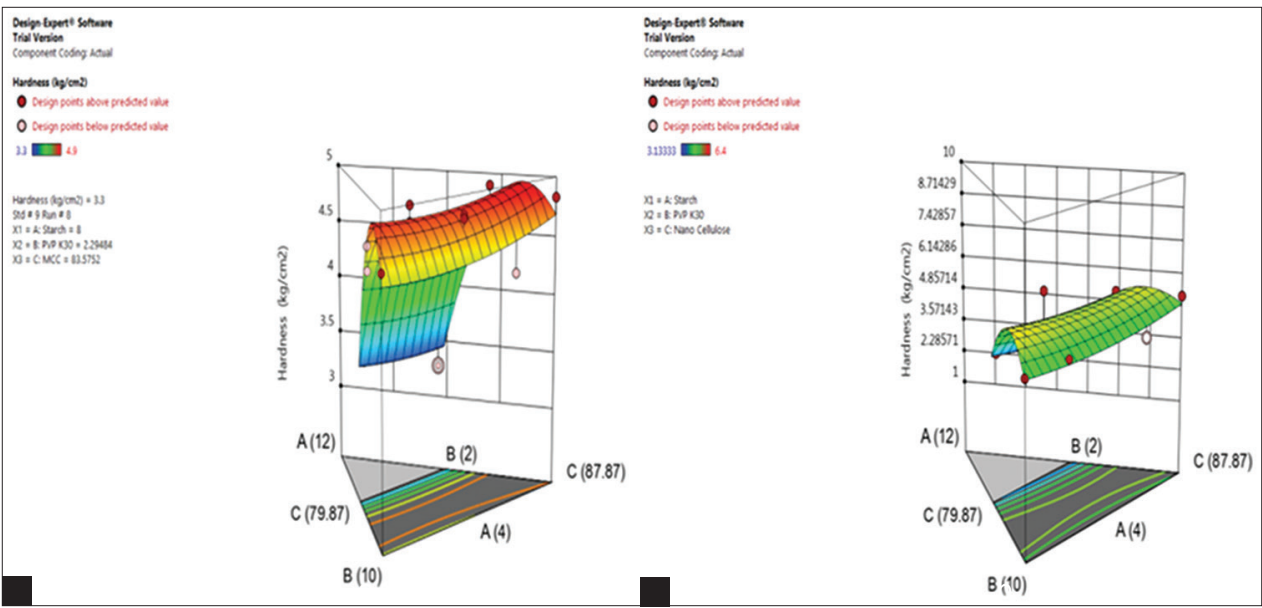

Fig. 5: Response surface plot for hardness a) MCC PH200 b) AH-NC 


\section{DT of GLB tablets (R5)}

Model $F$-value for MCC PH200 is 221.25 and for AH-NC is 6.67 implies that the model is significant. The results of multiple regression analysis indicate a fairly high value of correlation coefficient, i.e., 0.9866 for MCC $\mathrm{PH} 200$ and for $\mathrm{AH}-\mathrm{NC}$ is 0.8771 . It is concluded that the value of the DT can be predicted within the design space, with fair accuracy. The interaction terms are statistically significant in nature as shown in Table 9.

The coefficient associated with starch is negative, i.e., -742.6 for MCC PH200 and -733.13 for AH-NC. As shown Fig. 7, if the amount of starch is increased in the powder blend, the DT of the tablets will reduce.

\section{T90 of GLB tablets (R6)}

Model F-value for MCC PH200 is 2.05 and for AH-NC is 4.81 implies that the model is significant. The results of multiple regression analysis indicate a fairly high value of correlation coefficient, i.e., 0.9325 for MCC PH200 and for AH-NC is 0.8405. It is concluded that the value of the T90 can be predicted within the design space, with fair accuracy. The interaction terms are statistically significant in nature as shown in Table 10.

Table 8: Full model in coded form for friability

\begin{tabular}{|c|c|c|c|c|c|c|}
\hline & A & B & C & $\mathrm{AB}$ & AC & BC \\
\hline \multicolumn{7}{|l|}{ MCC PH 200} \\
\hline Friability & 2.57209 & 0.680256 & 0.556855 & -2.90677 & -3.3165 & 1.50394 \\
\hline $\mathrm{p}$ & 0.0010 & 0.0010 & 0.0010 & $<0.0001$ & $<0.0001$ & $<0.0001$ \\
\hline \multicolumn{7}{|l|}{ AH-NC } \\
\hline Friability & 0.49526 & 0.9097 & 1.08407 & -1.04139 & -0.484124 & -0.22969 \\
\hline $\mathrm{p}$ & $<0.0001$ & $<0.0001$ & $<0.0001$ & 0.0013 & 0.0728 & 0.0186 \\
\hline
\end{tabular}

MCC: Microcrystalline cellulose, AH-NC: Acid hydrolysed-nanocellulose

Table 9: Full model in coded form for disintegration time

\begin{tabular}{|c|c|c|c|c|c|c|}
\hline & A & B & C & AB & AC & BC \\
\hline \multicolumn{7}{|c|}{ МCC РН 200} \\
\hline DT & -742.607 & 41.6313 & 177.117 & 1593.51 & 1836.66 & 10.2776 \\
\hline $\mathrm{p}$ & $<0.0001$ & $<0.0001$ & $<0.0001$ & $<0.0001$ & $<0.0001$ & 0.7028 \\
\hline \multicolumn{7}{|c|}{$\mathrm{AH}-\mathrm{NC}$} \\
\hline DT & -733.137 & 34.7646 & 196.026 & 1588.38 & 1613.75 & 134.527 \\
\hline $\mathrm{p}$ & 0.0075 & 0.0075 & 0.0075 & 0.0032 & 0.0032 & 0.3661 \\
\hline
\end{tabular}

MCC: Microcrystalline cellulose, AH-NC: Acid hydrolysed-nanocellulose, DT: Disintegration time

Table 10: Full model in coded form for T90

\begin{tabular}{|c|c|c|c|c|c|c|}
\hline & A & B & C & $\mathbf{A B}$ & AC & BC \\
\hline \multicolumn{7}{|c|}{ MCC PH 200} \\
\hline T90 & 91.6893 & 35.8989 & 44.1256 & -131.778 & -167.588 & -37.2486 \\
\hline $\mathrm{p}$ & 0.2715 & 0.2715 & 0.2715 & 0.0979 & 0.0459 & 0.1660 \\
\hline \multicolumn{7}{|l|}{$\mathrm{AH}-\mathrm{NC}$} \\
\hline T90 & 20.4789 & 29.811 & 28.5094 & 71.9557 & 25.4957 & 1.27329 \\
\hline $\mathrm{p}$ & 0.0071 & 0.0071 & 0.0071 & 0.0822 & 0.5170 & 0.9231 \\
\hline
\end{tabular}

MCC: Microcrystalline cellulose, AH-NC: Acid hydrolysed-nanocellulose

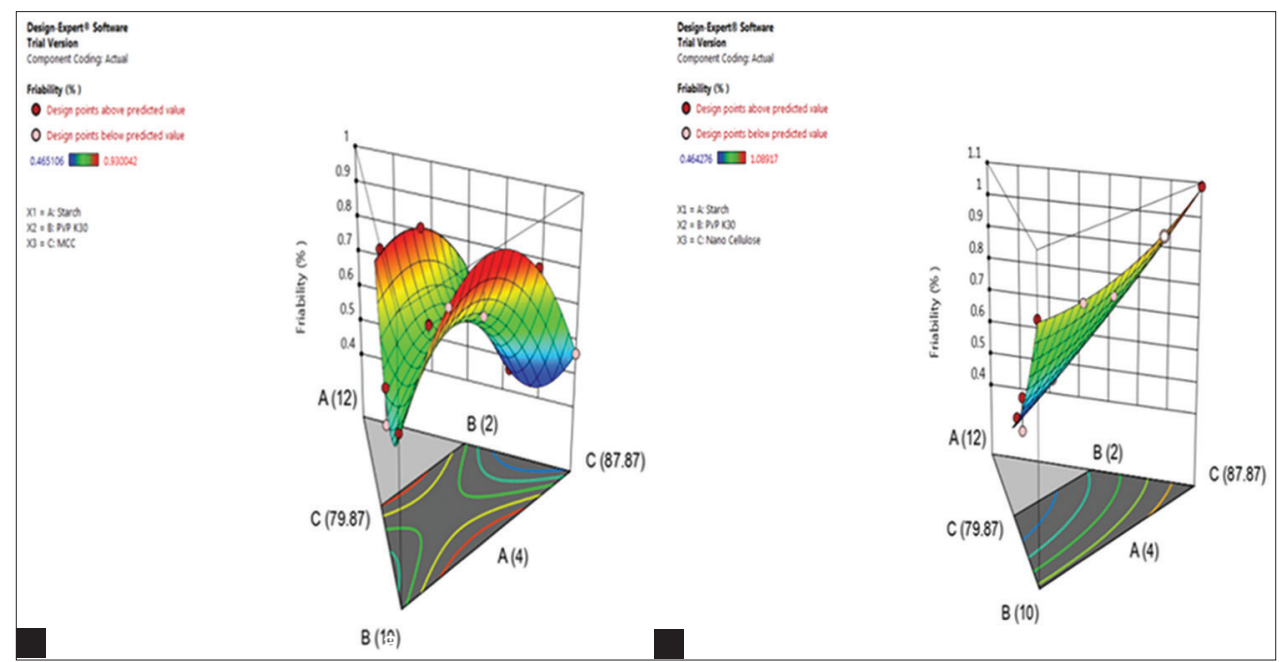

Fig. 6: Response surface plot for friability a) MCC PH200 b) AH-NC 
PVP K30 and MCC PH200/AH-NC have positive coefficients as shown in Fig. 8.

\section{Overlay plot for GLB tablet}

To check the predictive ability of all the mathematical points, two points were randomly chosen as shown in Fig. 9 for MCC PH200 and AH-NC.
A composition with 7.71\% starch, 3.91\% PVP K30, and 82.23\% MCC PH200 showed acceptable values of dependent variables $(\mathrm{CI}=13.36, \mathrm{AR}=32.30$, hardness $=3.73$, friability $=0.84, \mathrm{DT}=147.69 \mathrm{sec}$, and $\mathrm{T} 90=23.90 \mathrm{~min}$ ). A composition with $4.28 \%$ starch, $7.60 \%$ PVP K30, and $81.97 \%$ AH-NC showed acceptable values of dependent variables $(\mathrm{CI}=7.11, \mathrm{AR}=32.4$, hardness $=4.77$, friability $=0.86, \mathrm{DT}=129 \mathrm{sec}$, and $\mathrm{T} 90=31 \mathrm{~min}$ ).

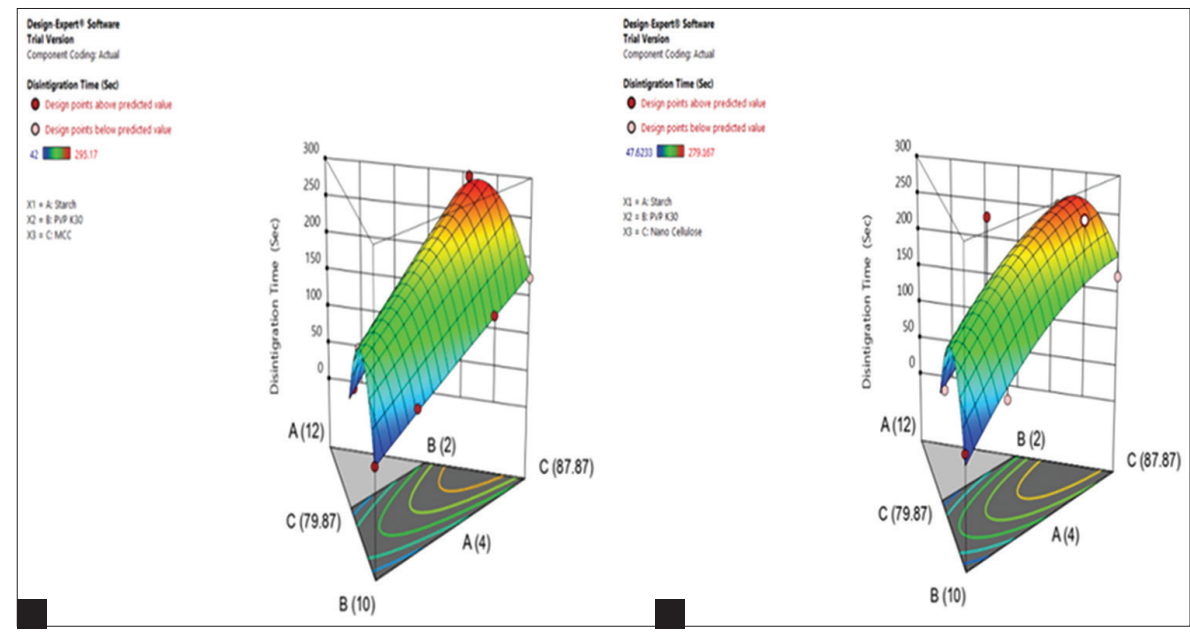

Fig. 7: Response surface plot for disintegration time a) MCC PH200 b) AH-NC

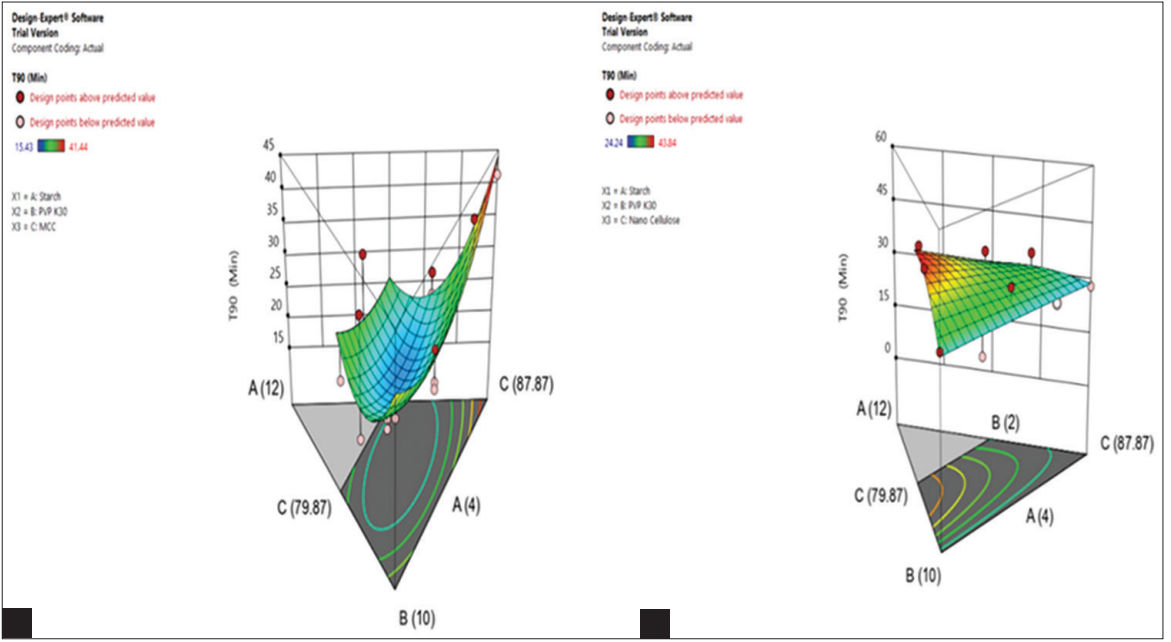

Fig. 8: Response surface plot for T90 a) MCC PH200 b) AH-NC

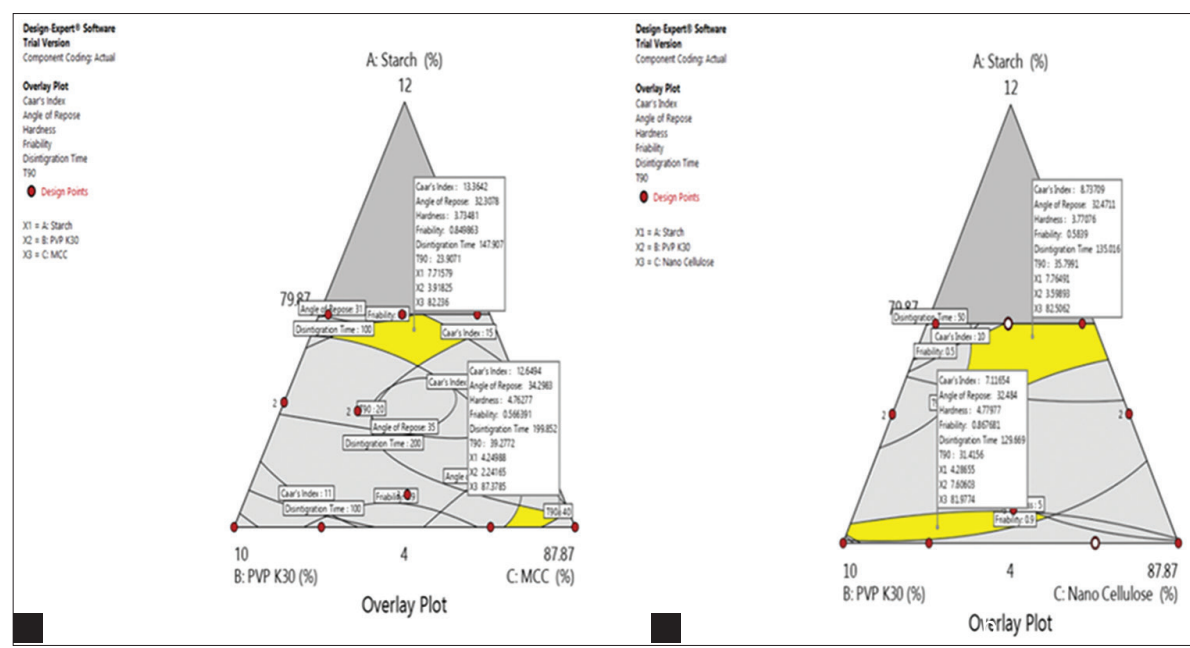

Fig. 9: Overlay plot for glibenclamide tablet using a) MCC PH200 b) AH-NC 


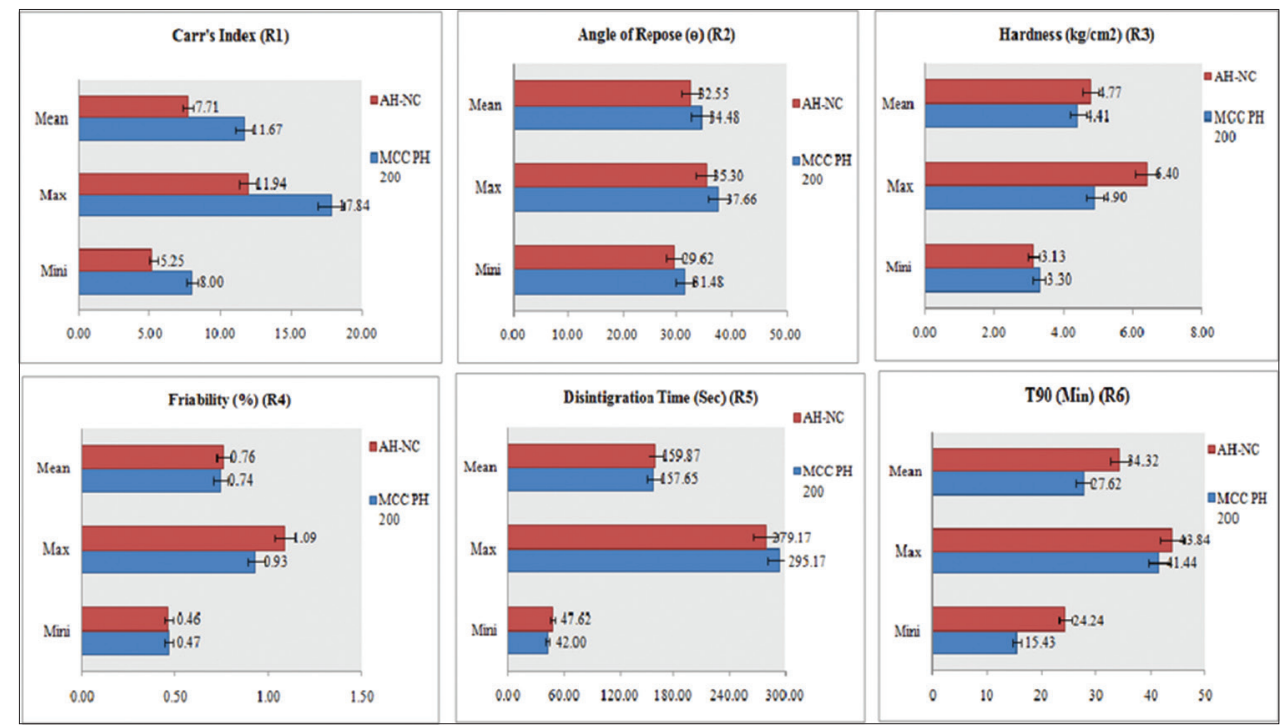

Fig. 10:Comparison between MCC PH200 and AH-NC

\section{DISCUSSION}

Good flow is one of the primary requirements for high-speed tablet press and as shown in Fig. 10. CI for AH-NC was 5.24 (low), 7.7 (mean), and 11.9 (high), i.e., good to excellent flow while for MCC PH200, it was 8 (low), 11.17 (mean), and 17.84 (high), i.e., fair to excellent flow. An AR for AH-NC was 29.62 (low), 32.55 (mean), and 35.3 (high), i.e., good to excellent flow while for MCC PH200, it was 31.48 (low), 34.48 (mean), and 37.66 (high), i.e., good to fair flow [18]. The hardness of the tablets depends on interparticle bonding and it is important for maintenance of tablet shape during manufacture and transit. For an average tablet, the required hardness is $4 \mathrm{~kg} / \mathrm{cm}^{2}$ [18]. In case of AH$\mathrm{NC}$, hardness was 3.13 (low), 4.77 (mean), and 6.4 (high) while for MCC PH200, it was 3.3 (low), 4.41 (mean), and 4.9 (high). The major reason for better consolidation of particles in AH-NC could be the presence of small particles, wherein stronger particle-particle bond might have formed. The values of friability, DT, and T90 were almost identical in both the cases. Based on these results, it can be further concluded that problems of weight variation and content uniformity variation were not observed in the case of AH-NC. Hence, between AHNC and MCC PH200, AH-NC is a better choice for large-scale tablet production.

\section{CONCLUSION}

Good quality tablets are dependent on attributes of diluents as they are used in the formulation to increase the bulk of formulations and to bind other inactive ingredients with the active pharmaceutical ingredients (APIs). GLB being a low-dose API should require a large fraction of diluent. Therefore, the attributes of diluents such as MCC PH200 and AH-NC become extremely important as they influence the quality of finished tablets. The present study focusing on powder flow properties, confirms the usage of AH-NC prepared from agricultural waste as an effective direct compressible vehicle for formulation design and product development when compared to MCC PH200. Furthermore, it is anticipated, this work will kindle more research and faith toward utilization of natural excipient extracted from agricultural waste in the solid oral dosage forms. Finally, based on the results of multiple regression analysis and ANOVA, it can be concluded that the three main effects, i.e., X1: Starch, X2: PVP K30, and X3: MCC PH200/AH-NC are critical material attributes.

\section{ACKNOWLEDGMENT}

Authors are thankful to the Department of Pharmaceutics and Pharmaceutical Technology, L. M. College of Pharmacy, Ahmedabad, Gujarat, India, for providing all the facilities throughout the work.

\section{AUTHORS' CONTRIBUTIONS}

Guidance and supervision for the research work were done by Dr. Yamini D. Shah. Experimental work, development, and optimization of the formulations and writing of this manuscript were done by Mrs. Roshni S. Vora.

\section{CONFLICTS OF INTEREST}

All authors have none to declare.

\section{REFERENCES}

1. Siro I, Plackett D. Microfibrillated cellulose and new nanocomposite materials: A review. Cellulose 2010;17:459-94.

2. Peng BL, Dhar N, Liu HL, Tam KC. Chemistry and applications of nanocrystalline cellulose and its derivatives: A nanotechnology perspective. Can J Chem Eng 2011;89:1191-206.

3. Rajinipriya M, Nagalakshmaiah M, Robert M, Elkoun S. Importance of agricultural and industrial waste in the field of nanocellulose and recent industrial developments of wood based nanocellulose: A review. ACS Sustain Chem Eng 2018;6:2807-28.

4. TAPPI. Summary of International Activities on Cellulosic Nanomaterials Conference: 2015

5. Zimmermann T, Pohler E, Geiger T. Cellulose fibrils for polymer reinforcement. Adv Eng Mater 2004;6:754-61.

6. Lu J, Wang T, Drzal LT. Preparation and properties of microfibrillated cellulose polyvinyl alcohol composite materials. Compos Part A 2008:39:738-46.

7. Nakagaito AN, Fujimura A, Sakai T, Hama Y, Yano H. Production of microfibrillated cellulose (MFC)-reinforced polylactic acid (PLA) nanocomposites from sheets obtained by a papermaking-like process. Compos Sci Technol 2009;69:1293-7.

8. Gabr MH, Elrahman MA, Okubo K, Fujii T. Effect of microfibrillated cellulose on mechanical properties of plain-woven CFRP reinforced epoxy. Compos Struct 2010;92:1999-2006.

9. Gandhi TP. Sulphonylureas second generation drugs. Indian Drugs 1978;6:163-5.

10. Balagani PK, Irisappan SC, Korlakunta NJ. Formulation development and evaluation of glibenclamide loaded eudragit RLPO microparticles. Int Curr Pharm J 2013;2:196-201.

11. Mohammed A, Mohd A, Abdul A, Abul KN, Yasmin S, Asgar A. Application of box-behnken design for preparation of glibenclamide loaded lipid based nanoparticles: Optimization, in vitro skin permeation, drug release and in vivo pharmacokinetic study. J Mol Liq 2016;219:897-908.

12. Food and Drug Administration. Quality by Design for ANDAS: An Example for Immediate-Release Dosage United States: Food and Drug Administration; 2015.

13. Nasr M, Migliaccio G, Allen B, Baum R. FDA's pharmaceutical quality initiatives. Pharm Tech 2008;32:54-72. 
14. Kumar BS, Saraswathi R, Kumar KV, Jha SK, Venkates DP, Dhanaraj SA, et al. Development and characterization of lecithin stabilized glibenclamide nanocrystals for enhanced solubility and drug delivery. Drug Deliv 2014;21:173-84.

15. Guan J, Han J, Zhang D, Chu C, Liu H, Sun J, et al. Increased dissolution rate and oral bioavailability of hydrophobic drug glyburide tablets produced using supercritical $\mathrm{CO} 2$ silica dispersion technology. Eur J Pharm Biopharm 2014;86:376-82.

16. Jeevana JB, Mounika M. Assessment of self-extracted cellulose from oryza sativa for design of controlled drug delivery system of dalfampridine. Asian J Pharm Clin Res 2019;12:338-45.

17. Mura P, Furlanetto S, Cirri M, Maestrelli F, Marras AM, Pinzauti S, et al. Optimization of glibenclamide tablet composition through the combined use of differential scanning calorimetry and D-optimal mixture experimental design. J Pharm Biomed Anal 2005;37:65-71.

18. The United State Pharmacopoeia (USP), National Formulary. Rockville,
MD, USA: United State Pharmacopeial Convention; 2011.

19. Hausner H. Friction conditions in a mass of metal powder. Int J Powder Metall 1967;3:7-13.

20. Jaya S, Divya S. Formulation and in vitro evaluation of matrix tablets of metoclopramide hydrochloride. Int J Appl Pharm 2019;11:25-30.

21. Lachman L, Libermann HA, Kanig JL. The Theory and Practice of Industrial Pharmacy. $3^{\text {rd }}$ ed. Philadelphia (USA): Bombay: Varghese Publisher House; 1991. p. 297-303.

22. Amrita S, Vaibhav R, Varsha K. Formulation development and evaluation of fast dissolving tablet of ramipril. Int J Pharm Pharm Sci 2015;7:127-31

23. Nawal AR, Mohammad SJ, Formulation and in vitro evaluation of piroxicam microsponge as a tablet. Int $\mathrm{J}$ Pharm Pharm Sci 2016;8:104-14.

24. The United State Pharmacopoeia (USP), National Formulary. Rockville, Md, USA: United State Pharmacopeial Convention; 2000. 